${ }^{\mathrm{I}}$ Universidade Estadual de Campinas (Unicamp), Departamento de Sociologia, Campinas, SP, Brasil renai3ıI@terra.com.br

Renato Ortiz'

\title{
AS CELEBRIDADES \\ COMO EMBLEMA SOCIOLÓGICO
}

\section{APRESENTAÇÃO DO PROBLEMA}

Existe atualmente uma ampla literatura sobre as celebridades, ela é sobretudo de origem norte-americana e britânica, embora o tema tenha se expandido a pesquisadores de outros países. Entretanto, essa abundância de textos não deixa de transparecer um certo incômodo: por que o interesse pela temática nas ciências sociais se deu tão tardiamente? Seria o hiato entre a existência do fenômeno e o seu reconhecimento por uma determinada área de conhecimento um simples descaso ou representaria ele algo mais significativo? Uma resposta possível, sugerida em inúmeros artigos e livros sobre o assunto (a bibliografia é extensa, mas pouco consistente do ponto de vista teórico), é que as ciências sociais teriam ignorado a questão devido à sua vocação elitista. Tratase de uma resposta plausível, mas pouco convincente. Claro, existem objetos "maiores" (Estado, partidos, classes sociais, modernidade) e "menores" (vida cotidiana), consagrados pela tradição do pensamento sociológico; como diria Bourdieu, o campo científico cultiva suas próprias ilusões, porém, para os que estão familiarizados com o debate sobre cultura de massa, cultura popular, meios de comunicação, transformações tecnológicas, esse tipo de explicação é bastante precário. A sociologia da comunicação de massa não tinha como objeto a cultura erudita, a música séria, dizia Adorno, mas justamente o seu polo oposto, o gosto de massa. Talvez pudéssemos dizer que na década de I940, nos Estados Unidos (aí surge o debate sobre cultura de massa), a relação entre eli- 
tismo e ciências sociais fazia algum sentido. Nessa época vários autores não hesitavam em dizer que o conceito de cultura popular era o contraponto negativo da grande arte. Mas as ciências sociais possuem uma história, e a temática do popular, dos meios de comunicação, ou seja, dos assuntos "menores", faz parte de sua tradição. Nesse sentido, o argumento do elitismo se enfraquece; se o fenômeno das celebridades é percebido tardiamente, isso se dá em função de outros parâmetros. Gostaria, neste texto, de explorar essa ausência, o que de maneira preliminar denominarei da seguinte maneira: as celebridades não constituíam ainda um emblema sociológico. Procurarei desenvolver posteriormente a ideia de emblema, mas, desde logo sublinho, ela se vincula a um conjunto de transformações sociais que eram latentes, embora não se encontrassem ainda visíveis para todos nós. Daí o hiato entre latência e explicitação, potência e realização.

Pode-se dizer que, apesar de tardia, rapidamente, mas por partes, foi-se constituindo uma narrativa da emergência de uma celebrity culture ou de uma celebrity society (utilizo os termos consagrados pela literatura em inglês). É possível segui-la pela bibliografia especializada e também por alguns balanços bibliográficos elaborados pelos autores da área (ver Harmon, 2005; Ferris, 2007; Heinich, 20 I r a e 20 I b). Deixando-se de lado o que denominaríamos precursores (irei trabalhá-los em seguida), pode-se alinhar um conjunto de textos geralmente considerados canônicos: Daniel Boorstin (I97 I), "From hero to celebrity: the human pseudo-events"; Richard Schikel (1985), Intimate strangers; Irving Rein, em parceria com Philip Kotler, Michael Hamlin e Martin Stoller (1987), High visibility; Leo Braudy (I986), The frenzy of renown: fame and its history. ${ }^{\mathrm{I}}$ Boorstin inaugura uma linhagem temática, seu ensaio explicitamente nomeia um objeto, as celebridades, procurando apreendê-lo de maneira arguta e crítica. O livro de Schikel tem a virtude de considerá-las na sua relação com o público, o título é sugestivo, elas seriam para nós "íntimos estranhos". Distantes, se encontrariam próximas de nossos sonhos e desejos. Braudy faz uma incursão pela história, busca entender como a fama é representada em diversas configurações sociais do passado. Entretanto, todos esses escritos são aproximações ainda bastante incompletas do tema; ao lê-los percebe-se que a intuição dos autores sobrepõe-se a uma análise sistemática da problemática em questão. Dificilmente poderíamos classificá-los dentro de uma área específica do conhecimento. High visibility é talvez a única exceção (Rein et al., I987). Seus autores pertencem a uma área disciplinar determinada: marketing e administração de empresas. Eles não se contentam em compreender como "as pessoas transformam-se em celebridades", ou seja, como se estrutura uma indústria que as molda dessa maneira; seu intuito inscreve-se numa perspectiva prático-teórica: utilizá-las como suporte para a promoção das marcas e produtos lançados no mercado. $\mathrm{Na}$ verdade, desde a década de 1970 existe toda uma literatura que se interessa pelas questões relativas ao uso das celebridades como instrumento de marketing; 
diversos estudos são realizados demonstrando a relação entre elas e a confiança do consumidor nos produtos anunciados. Os autores partem do princípio de que a credibilidade e a confiança de uma pessoa conhecida pelo grande público podem ser transferidas para as mercadorias a comercializar. Nesse sentido, são realizadas várias pesquisas para medir o grau de confiabilidade que um produto possui ao vincular sua imagem à notoriedade de alguém. "Cientificamente", essa é a ilusão compartilhada, ou seja, por meio de modelos matemáticos, procura-se demonstrar a eficácia desse tipo de estratégia (ver Friedman \& Friedman, I979; Friedman et al., I978). Não se deve confundir o uso das celebridades como instrumento de promoção dos produtos com os estudos disciplinares de marketing e administração de empresas. O primeiro tipo de prática é antigo, principalmente na indústria cinematográfica; para Hollywood, desde o início de sua história, as grandes estrelas sempre fizeram parte do apelo publicitário. Particularmente nos Estados Unidos, onde precocemente o capitalismo se mescla ao universo de entretenimento, o espaço público no qual os indivíduos de renome são reconhecidos é fortemente marcado pela razão de mercado. Como observa Joshua Gamson (I992), o mundo das celebridades está intimamente associado a uma linha de produção da fama. Entretanto, os estudos sobre as celebridades, feitos pela área disciplinar, marketing e administração de empresas, são posteriores. Para que isso acontecesse não era suficiente a mera existência de uma prática enraizada entre os profissionais do meio empresarial; foi necessário que o campo científico de atuação desses personagens estivesse consolidado: desenvolvimento de áreas temáticas distintas, consagração de determinados métodos de análise, institucionalização da disciplina, enfim, sedimentação de uma tradição intelectual de discussões e debates. Podese argumentar que o prematuro pragmatismo que os homens de marketing nutrem pelas celebridades - elas auxiliam na venda de seus produtos -, tenha impulsionado o desenvolvimento dessa área acadêmica. Fica claro, porém, que tal atenção se antecipa em muito à das ciências sociais. Na verdade, isso não ocorre apenas em relação à questão que estamos discutindo; também a problemática da globalização, muito antes de ser tratada sociologicamente, já havia sido amplamente discutida entre os homens de negócios (particularmente no que se refere à posição das transnacionais no mercado global). Lembro que nos anos I980 as ciências sociais estavam mais interessadas na controvérsia modernidade versus pós-modernidade do que propriamente no debate sobre a globalização (ver Ortiz, 2009). A rigor, é somente na década de I990, ainda timidamente, que surge nas ciências sociais uma consideração maior pela problemática das celebridades. São desse período os textos de Joshua Gamson (I994) e David P. Marshall (I997), além de estudos esparsos sobre o tema (ver, por exemplo, Langbauer, I993). A partir da virada do século as referências bibliográficas se multiplicam; em pouco mais de uma década elas se acumulam, envolvendo áreas distintas como estudos culturais e comunicação. ${ }^{2}$ 


\section{EMERGÊNCIA DE UM TEMA}

Seriam as celebridades um fenômeno novo? Essa é uma pergunta que permeia a literatura que nos interessa. Uma resposta positiva, pelo menos em parte, justificaria um certo atraso no reconhecimento de algo em mutação. Quando Boorstin publica seu ensaio em I97 I ele não deixa dúvidas de que nos encontramos diante de algo recente.

Neste século, particularmente a partir de 1900, parece que descobrimos o processo de como a fama é manufaturada. Agora, pelo menos nos Estados Unidos, da noite para o dia, o nome de um homem pode transforma-se em algo familiar. A revolução gráfica subitamente nos deu, entre outras coisas, os meios de fabricação de ser bastante conhecido. Descobrir que nós (os espectadores de televisão, os frequentadores de cinema, os ouvintes de rádio, os leitores de jornais e revistas) e nossos servidores (a televisão, os produtores de rádio, os editores de jornais e revistas, os escritores de publicidade) podemos rapidamente, e de maneira eficiente, conferir fama aos homens, nos leva a equivocadamente considerar que a fama é um atributo da grandeza (Boorstin, I97r: 47). ${ }^{3}$

Richard Schickel (I985: 23) também partilha o mesmo ponto de vista: "Essa coisa de celebridade não existe antes do início do século XX. Na verdade, embora nas segunda e terceira décadas desse século as pessoas conhecidas começassem a se comportar da maneira que agora identificamos como sendo de celebridades, o termo, no seu sentido comum, só veio a ser utilizado recentemente". Muitos autores enfatizam essa dimensão de atualidade do fenômeno em questão. As celebridades dependeriam da alta visibilidade de suas individualidades, isso só seria possível se o fluxo de informação para o grande público fosse realmente intenso. Nesse sentido, a qualidade dos meios de comunicação, ou seja, sua eficácia tecnológica e comunicativa, seria intrínseca ao próprio fenômeno. A invenção da fotografia e do cinema, a proliferação da imprensa de massa, o surgimento da publicidade moderna, o advento do rádio e da televisão tornam-se elementos imprescindíveis para a constituição de uma celebrity culture. Cito um entre inúmeros autores que reiteram a importância dessas transformações: "Celebridade, tal como a conhecemos hoje, foi criada pela mídia de massa moderna. Ele começa com a fotografia no início do século XIX, quando, pela primeira vez na história, as pessoas puderam olhar suas imagens em outra coisa que não fosse um espelho" (Ruebsaat, 2007: 9; ver também Leslie, 20I I).

No entanto, a pergunta anterior pode receber uma resposta negativa. Haveria uma história das celebridades que remontaria à Antiguidade. Essa é a intenção de Leo Braudy ao refutar a tese de sua emergência recente; ele pretende demonstrar a continuidade da ideia de fama desde os primórdios da humanidade. Como justificar a presença desse traço atemporal ao longo do desenvolvimento humano? Ele nos diz: “o desejo de reconhecimento é parte da natureza humana, sensível à estrutura social e aos modos de comunicação 
existentes na sociedade"; o que lhe permite afirmar: "a história da fama é em grande parte a história das transformações de como os indivíduos procuram chamar a atenção dos outros e, não de maneira incidental, como ganham poder em relação a eles" (Braudy, I986: 3). Outros autores têm um raciocínio semelhante ao seu: "Sendo o que é, a natureza humana faz com que sempre tenham existido pessoas aflitas por um desejo patológico de atenção. Um exemplo chocante envolve o incendiário chamado Heróstrato, que colocou fogo no grande templo de Artemis em Éfeso, na Turquia, em 348 a.C. Sob tortura ele confessou que foi conduzido por um único motivo, o apetite insaciável pela celebridade" (Garland, 20Io: 484-485). Os problemas em relação a esse tipo de argumentação são evidentes; pressupõe-se a existência de uma natureza humana nunca explicitada. Uma vez aceita essa hipótese, a história seria apenas uma condição na qual a noção de fama se realizaria. Há, ainda, outra dificuldade: desconhece-se toda uma história do indivíduo e do individualismo, como se fosse possível apreendê-la fora do contexto social no qual se insere. Ora, Marcel Mauss já nos havia ensinado que o conceito de pessoa reveste-se de formas diferentes em função da religião, dos costumes, das estruturas sociais e das mentalidades. O advento do indivíduo moderno, que ordena o passado à sua semelhança, é, na verdade, um traço específico de uma determinada configuração histórica. Esse é um debate clássico nas ciências sociais (aliás, com um viés bastante eurocentrista) (ver Mauss, I968). Postular um estatuto universal da celebridade é projetar no passado uma categoria que faz sentido no mundo em que vivemos. Esse anacronismo, pecado mortal para todo historiador, termina por incentivar um senso comum que de maneira pouco convincente contenta-se em revelar o passado à luz de um espelho distorcido. Braudy pode, assim, alinhar figuras díspares como: Alexandre, o Grande, Júlio Cesar, o assassino de Wichita que imitava os crimes de Jack, o Estripador, Cleópatra, Jesus, Maomé, Joana D’Arc, Shakespeare. Todos seriam pessoas famosas e poderiam ser agrupados em torno da mesma classificação. Entre Madonna ou Angelina Jolie, entre os gregos ou romanos, haveria uma simples diferença de situação; entretanto, eles comungariam a natureza do mesmo fenômeno (ver Payne, 2009). A ideia da continuidade da fama, transmutando-se em celebridade, enfrenta ainda outro obstáculo. Trata-se de qualidades distintas. Esse é um aspecto reiteradamente discutido no corpo da literatura especializada, a diferenciação entre, de um lado, fama e renome, de outro, celebridade. Fred Ingliss (2010) observa que o termo celebridade substitui o velho conceito de "renome" associado a alguns personagens que desempenhavam determinadas funções (particularmente as altas funções). Por exemplo, um jurista ou um clérigo, sua aclamação derivava da realização de um ato específico. Entretanto, o renome trazia honra não tanto ao indivíduo em questão, mas ao ofício ao qual ele se integrava; o reconhecimento público não visava simplesmente a sua individualidade. David Marshall (I997), ao traçar a história do termo em inglês nos fornece um exemplo 
sugestivo de como ele se separa de suas conotações anteriores. Analisando o sentido da palavra nos dicionários ingleses (Oxford English e Webster's) ele mostra que ainda no século XIX conviviam significados bastantes distintos: "respeito devido aos cultos e cerimônias; pompa, solenidade"; "um rito solene ou cerimônia, celebração"; "a condição de ser exaltado ou falado; fama, notoriedade"; "pessoa de celebridade; pessoa celebrada; uma figura pública". Porém, The English Oxford Dictionnary registra que o primeiro uso impresso do termo, aplicado a uma pessoa, ocorre somente em I849. Um dado interessante pode ser encontrado no Dictionnaire Littré de la Langue Française (1872). Ao lado do sentido tradicional consagrado - "solenidade; pompa; renome" - surge agora um neologismo: "pessoa célebre, as celebridades de nosso tempo". É esta última acepção que irá definir o estatuto atual das celebridades, mas para isso foi preciso que elas definitivamente se desvencilhassem dos elos que as aprisionavam ao pretérito.

A invenção de novos termos, assim como a mudança do sentido de palavras antigas, é sugestiva posto que nos remete a contextos sociais distintos. Para nomear-se apropriadamente uma realidade emergente é necessário um neologismo ou a criação de termos novos. Eric Hobsbawm (2009) observa que o período que se segue à Revolução Industrial é farto em significação e ressignificação das palavras, surgem denominações que nos remetem diretamente à configuração da sociedade moderna: indústria, industrial, fábrica, capitalismo, classe trabalhadora, classe média, capitalismo, estradas de ferro, proletariado, científico, ideologia etc. Essa profusão terminológica deriva da necessidade de compreender as profundas mudanças sociais, econômicas e políticas em curso. Eu diria que celebridade faz parte do rol desses termos recentes, porém, paradoxalmente, isso passa desapercebido, ou seja, ele nomeia algo que se encontra em processo de gestação, mas não configura ainda uma categoria instituída capaz de desfrutar de prestígio no mundo burguês em formação. De fato, o termo não possui a reputação que modernidade encerra, neologismo forjado por Baudelaire para apreender a condição do artista moderno na era da multidão e da reprodutibilidade técnica; ou civilização, cujo passado nos remete aos escritos de Mirabeau e Turgot. ${ }^{4}$ David Marshall (I997) nos diz que celebridade, pelo menos em inglês, não contém uma grande bagagem cultural. Isso talvez se deva ao fato de que a noção de "pessoa célebre" se encontra marcada por uma certa dubiedade, um ar de inautenticidade diluindo as virtudes da verdadeira fama. Uma frase do século XIX - "eles (os sucessores de Spinoza) têm celebridade, Spinoza tinha fama" - capta bem esta ambiguidade. O verdadeiro estaria do lado da fama, o inautêntico da celebridade. O hiato ao qual eu me referia, entre potência e realização, existir e ser, insere-se dessa forma na expressão terminológica que apreende um mundo em transformação. Se visibilidade é uma dimensão intrínseca ao fenômeno das celebridades, ironicamente o termo que as nomeia desfruta de um razoável grau de opacidade. 
Mas quais seriam os aspectos recentes a que ele se refere? Menciono alguns: indivíduo, espaço público, meios de comunicação; dimensões que sociologicamente caracterizam a modernidade. A celebridade condensa em si os traços de uma individualidade própria, e essa é a marca pela qual é reconhecida. O estamento, a classe social, o pertencimento a um grupo tornam-se secundários (mas não apagados) diante da presença da idiossincrasia pessoal. O reconhecimento por sua vez pressupõe a existência de pessoas que possam identificá-la como "íntimos estranhos", próximos e distantes. O advento do indivíduo moderno, livre do peso da tradição, é uma condição necessária para a manifestação do fenômeno. Outro aspecto refere-se ao surgimento de uma esfera pública burguesa; isso terá, como nos mostra Habermas, implicações políticas e sociais. Deixo de lado a dimensão política para insistir sobre um ponto específico: propiciar a algumas pessoas a condição de visibilidade. Esse é um atributo decisivo na definição da problemática que nos interessa. ${ }^{5} \mathrm{~A}$ individualidade identificada só pode se afirmar no interior do espaço público, ele é o território de sua representatividade. Para transformar-se em algo reconhecível o indivíduo não pode estar confinado à sua privacidade; esta deve ser projetada num terreno compartilhado pela "opinião pública". Por fim, os meios de comunicação, eles conferem às celebridades um caráter de ubiquidade. Chris Rojek (200I), ao diferenciar as noções de celebridade e renome, chama a atenção para esse aspecto. O renome seria uma distinção social dentro de um grupo limitado de pessoas; a fama estaria circunscrita a um campo com fronteiras bem delineadas. Em contrapartida, a celebridade teria como precondição a distância social, o fato de transcender o horizonte dos grupos e agrupamentos particulares. Entretanto, a ubiquidade exige a materialização de meios técnicos adequados, são eles que veiculam a imagem célebre para "todos os lugares". Do ponto de vista sociológico, as celebridades são fruto da modernidade. Uma outra maneira de abordarmos o problema é por meio da história. Ao qualificar esse processo, os historiadores irão datá-lo e compreendê-lo a partir de um conjunto de transformações. Fred Inglis (20I0) o situa em momentos distintos: a vida urbana na Londres do século XVIII: teatro, jornais, lazer da classe alta; Paris do século XIX: reformas do barão Haussmann, a vida boêmia; a vida urbana na Nova York do século XIX. Espaço público e urbanidade encontram-se assim intimamente mesclados. Antoine Lilti (2014) considera que a invenção das celebridades faz-se entre i750 e i850. Durante o século XVIII teria surgido o embrião de uma sociedade do espetáculo na qual os traços individuais de alguns escritores, atores e atrizes de teatro, seriam projetados no espaço público. Voltaire torna-se o "homem mais célebre da Europa", ele não seria apenas um nome, mas também, um rosto; retratos, bustos e gravuras o representavam. Dessa forma, antes mesmo da invenção da fotografia, a importância da representação iconográfica valorizaria entre as pessoas as virtudes dos que seriam célebres. No caso dos Estados Unidos, uma forma de se apreender o surgimento desse fenômeno, é pela emergência do "jornalismo de 
celebridades" (Ponce de Leon, 2002). Trata-se de um tipo de narrativa que valoriza sobretudo a esfera privada da pessoa: entrevistas, fofocas, biografias. Desenvolve-se mesmo um tipo de fotografia conhecida como "cândidas fotografias de celebridades", portanto, um jornalismo que se afasta do relato das notícias gerais, das reportagens, das informações, centrando-se na idiossincrasia do sujeito retratado.

Não obstante, o desenvolvimento desse fenômeno não possui um movimento teleológico como às vezes lhe é atribuído. Longe de ser contínuo, ele parece ser lento, fragmentado e desigual. Em relação ao século XVIII, algumas dúvidas persistem. Stella Tillyard faz observações interessantes a esse respeito. Ela pondera que nessa época é possível encontrar em cartas, romances e jornais, expressões como: "o celebrado Dr. Johnson"; "a estação do ano mais celebrada"; ou David Hume escrevendo sobre Rousseau, censurando sua vaidade para "obter celebridade". Mas nunca uma dimensão fundamental ao fenômeno é nomeada, a qualidade de ser celebridade atribuída a um indivíduo. Por isso a autora critica a narrativa da celebrity culture ao confeccionar um passado a partir de um referencial contemporâneo.

Na satisfação de nos reconhecer no espelho que o passado aparentemente nos fornece, temos tendência a esquecer de fazer algumas perguntas pertinentes. Estamos olhando para nós mesmos ou para algo inteiramente diferente? Não estaríamos esquecendo que olhamos para uma imagem de nós mesmos, quando subjacente ao que se encontra refletido no espelho repousa uma outra imagem, um pouco obscura, refratária ao presente, mas inda assim recuperável? (Tillyard, 2005: 20).

Se essas críticas são válidas para o século XVIII, creio que é também possível encontrar, ao longo do XIX, uma série de indícios que confirmam a incipiência do fenômeno em questão. Basta analisarmos o escopo de significados que abrange a noção de celebridade. Ela não se restringe às pessoas realmente famosas, identificadas na amplitude do espaço público. Olhando-se a lista de livros publicados no qual o termo recorrentemente aparece, algumas incongruências podem ser apontadas. Devonshire celebrities (I 869) revela que uma certa famíla Acland residia na paróquia de Landkey, cuja origem poderia ser traçada desde I I54; que Charles Babbage, notável matemático e astrônomo, era nativo do condado de Devon; aprendemos ainda sobre a ilustre linhagem dos bispos desconhecidos de Crediton. Há livros como Celebrities: little stories about famous folk (I923), ou Wild animals celebrity (I900). O termo se aplica também a grupos específicos: Harvard celebrities (I9OI) ou a publicações memorialistas: Many celebrities and a few others: a bundle of reminiscenses (I9I2). Celebridade refere-se a um conjunto de situações díspares indicando uma certa flexibilidade do significado que abrange. Não se trata de negar a existência de algo inconteste. A modernidade industrial de fato redefine a vida em sociedade, e a emergência de pessoas com alta visibilidade, integradas a um espaço público que se generaliza, é uma realidade. Mas há uma dimensão dessas "fi- 
guras públicas" (para usar a expressão de Lilti) que escapa ao nosso olhar do presente. Talvez pudéssemos resumir esse hiato por meio de um contraste: o fenômeno é real, mas não configura uma celebrity culture.

\section{AS CIÊNCIAS SOCIAIS E AS CELEBRIDADES}

Eu havia dito que anteriormente aos textos canônicos escritos nas décadas de I 970 e I 980 havia nas ciências sociais alguns precursores que tinham se voltado para a temática. Gabriel Tarde (I902) é um deles. Ele esboça, aliás, uma teoria do valor que visa compreender como os homens avaliam as pessoas, coisas e objetos. Esse valor, em si uma qualidade específica, seria mensurável, expressando em quantidade aquilo que é considerado. Assim, ao analisar a vida pública, ele fala em "valor-glória", ou seja, a notoriedade que algumas pessoas possuem. Como qualquer outro valor, ele poderia ser captado por um cálculo estatístico denominado, no caso, gloriomètre. Suas observações são, no entanto, breves e incompletas; Tarde, pelo fato de ser um autor esquecido entre os fundadores das ciências sociais, além de escrever em francês, ocupa uma posição marginal na bibliografia das celebridades, predominantemente escrita em inglês. ${ }^{5}$ Dos textos disponíveis em relação à problemática é possível, de maneira preliminar, ordená-los em ordem cronológica: Joseph Schneider (I936), "Fame and social origin"; Leo Lowenthal (I944), "The triumph of mass idols"; Orrin Klapp (I949), "Hero worship in America"; Edgar Morin (I957 e I962), Les stars e L'esprit du temps; Francesco Alberone (I963), L'élite senza potere. O artigo de Schneider, publicado em Social Forces, é talvez o que mais se afaste de nossas preocupações atuais. Ele se volta para a análise da distribuição dos homens de gênio entre as classes sociais de um determinado país. A fama encontra-se dessa forma diretamente associada ao talento e à genialidade de poucos indivíduos. Lowenthal (I984) parte de uma pesquisa empírica sobre as biografias publicadas nos Estados Unidos. Ele observa que no início do século XX a maioria das pessoas biografadas pertencia ao campo da política; em torno de I940 há uma inversão, e majoritariamente elas se associam ao mundo do entretenimento. Klapp, no ensaio que aparece na American Sociological Review, capta com sagacidade uma mudança de humor dos tempos. Logo na abertura do texto ele diz:

Na América frequentemente o grande homem é um atleta, alguém do mundo do entretenimento, uma pessoa que realizou fatos relativamente triviais, cuja preeminência em nossa escala de valor favorece comentários desfavoráveis relativos ao "materialismo" ou à "vulgaridade" do estilo de vida americano. Nos últimos anos tivemos um grande número desses heróis populares que contrastam com a integridade imaculada de nossos heróis nacionais ou mártires. Além dessa questão dos valores, a emergência desses heróis populares frequentemente associa-se ao distúrbio das forças sociais e políticas. O culto dos heróis de massa naturalmente conduz aos excessos, à devoção cega dos líderes. Quando ela não tem essas consequências, conduz geralmente à irracionalidade e à trivialidade da moda e do culto. De qualquer maneira, a força social se desfaz agindo de forma perturbadora no status quo (Klapp, I949: 53). 
Sublinham-se, portanto, as mudanças em curso na sociedade norteamericana. Do conjunto de referências que assinalei, certamente Morin e Alberone elaboraram os trabalhos mais sistemáticos; trata-se de livros, não apenas ensaios esparsos, que buscam desenvolver a questão da indústria cultural e da cultura de massa. Morin situa as estrelas de cinema no Olimpo; elas possuiriam uma dimensão mítica. Ao apresentar Les stars ao leitor ele informa que essas criaturas, semidivinas, originárias do espetáculo cinematográfico, lhe interessam enquanto mito moderno (Morin, I972: 7). Essa é uma dimensão em que suas pesquisas, em conjunto com outros colegas - penso particularmente em Barthes ${ }^{7}$-, serão trabalhadas no Centre de Communication de Masse fundado por Georges Friedmann. Dos autores que enumerei, talvez seja Alberone quem possua a consciência mais aguda do fenômeno em questão. Ele pondera que no mundo moderno existem personagens públicos que são objeto de curiosidade, admiração, interesse, e de crítica; a distância são cultuados por um "amor longínquo". Para dar conta dessa admiração extraordinária, ele lança mão do conceito weberiano de carisma; se Morin considera as estrelas habitantes de um mítico Olimpo, ele as faz descerem à Terra, compreendendo-as como seres dotados de carisma.

Não resta dúvida de que muitos dos argumentos trabalhados pelos precursores nos aproximam da temática tal como a conhecemos atualmente. De maneira convincente eles evidenciam a íntima relação entre espaço público e meios técnicos de comunicação. É como se a entrada no século XX cristalizasse as mudanças existentes no XIX. Não é fortuito que o cinema seja considerado uma espécie de objeto exemplar para muitas dessas reflexões; nessa época, sobretudo na Europa, a televisão não tinha ainda adquirido uma feição de massa. A indústria cinematográfica possui ainda uma dimensão internacional (não se reduz a Hollywood) promovendo em escala ampliada a visibilidade das atrizes e atores. Mesmo assim a leitura desses textos evidencia alguns problemas. Consideremos Klapp, por exemplo. Ele havia terminado sua tese de doutorado The hero as a social type em I948 e de certa maneira procurava expandir o horizonte de suas pesquisas ao considerar a emergência de um novo tipo de herói na sociedade norte-americana. A categoria herói é fundamental em sua abordagem metodológica, o que significa não haver uma ruptura entre ela e a noção de celebridade. Ele acreditava ainda que esse tipo social pode ser compreendido por meio de uma teoria geral que estabeleça sua "sequência genética".

Pensamos que o culto dos heróis possui uma sequência genética que nos conduz a um ciclo que se inicia com a emergência do herói popular. Podemos descrever as fases principais desse processo da seguinte maneira: (I) homenagem popular espontânea e desordenada, (2) reconhecimento formal da honra, (3) construção de uma imagem idealizada da imagem ou da lenda do herói, (4) comemoração do herói e (5) estabelecimento do culto (Klapp, 1949: 54). 
É dentro dessa perspectiva que é analisado o surgimento de um típico herói popular: Lindbergh. ${ }^{8}$ Seu feito, a travessia do Atlântico num voo solo entre Nova York e Paris, transforma-se num evento épico. É interessante observar que para Klapp o fenômeno de "contágio" é espontâneo, tudo se passa como se a figura de renome despertasse nas pessoas um sentimento de admiração irresistível, levando-as a se organizar para cultuá-la. Ora, se existe uma dimensão consensual na bibliografia sobre o tema é que a margem de espontaneidade prevalente nesse tipo de manifestação é mínima. Graeme Turner (2004) dedica toda a primeira parte de seu livro à "produção das celebridades" e Chris Rojek (200I) nos mostra que elas são uma "fabricação cultural"; seu impacto no público pode ter uma aparência espontânea, no entanto, elas são cuidadosamente mediadas por toda uma "cadeia de atração". Na verdade, entre o herói e a celebridade existe um espaço vazio preenchido pela indústria cultural; sem essa dimensão técnica e mercadológica, ela não conheceria o prestígio de que desfruta. Outro exemplo pode ser retirado da reflexão proposta por Edgard Morin. À primeira vista somos iludidos pelo brilho cintilante das estrelas no Olimpo - Greta Garbo, Gary Cooper, Jean Gabin, Audrey Hepburn, Brigitte Bardot, Burt Lancaster. Entretanto, o que lhe interessa são os arquétipos que esses nomes representam. Como nos mitos gregos, um arquétipo encerra um modelo exemplar de comportamento; a rigor, ele é coletivo, não constitui uma individualidade. Por isso Morin volta-se para o entendimento de temas como o amor e a aventura. Sua análise dos personagens femininos consegue identificar alguns tipos característicos: a virgem inocente com os olhos crédulos e os lábios entreabertos do cinema mudo; a grande prostituta das mitologias mediterrâneas; a vamp, misteriosa e mulher fatal. Do lado masculino temos os heróis cômicos, da justiça, da aventura, representações fílmicas de Teseu, Hércules, Lancelot. A análise que ele faz de James Dean é brilhante, entretanto, não é sua individualidade que lhe retém a atenção, a relação com a subjetividade de seus fãs ou o carisma intransferível para qualquer outro ator (Morin, I972). James Dean é a típica expressão da adolescência em geral e do adolescente norte-americano em particular. Ele traduz, de maneira exemplar, como um modelo, a dupla natureza de um jovem, oscilando entre os traços da infância que ainda perduram e o mundo adulto a sua frente. Considerar as estrelas mito é situá-las na esfera do coletivo; o traço de sua individualidade agrupa-se em torno de uma classificação que transcende suas personalidades. Por fim, uma última observação: nenhum desses textos utiliza a categoria celebridade. Os termos empregados oscilam entre, herói, estrela, sendo que Alberone prefere divo, relativo a divino, divindade, magnífico. Como um fenômeno pode ser plenamente compreendido sem que se tenha à disposição a categoria que o nomeia? 


\section{CELEBRIDADES E CULTURA DE MASSA}

Posso agora retornar à ideia inicial de emblema. Nos seus estudos sobre a globalização, procurando demarcar o tempo do globalismo do capitalismo industrial do século XIX, Octavio Ianni (I994) considera alguns temas clássicos da sociologia. Indivíduo, nação, mercado nacional, multidão, seriam emblemas de uma problemática específica: a modernidade. Mas o que é um emblema? Trata-se de uma representação gráfica que torna visível um determinado aspecto da realidade; de maneira taquigráfica ele "fala" de um contexto particular. O emblema não se esgota na materialidade de seu significante, o transcende e o ultrapassa. Durkheim costumava dizer que nas sociedades australianas o "totem é o emblema da tribo". Na sua materialidade, indício gravado na madeira ou desenhado na pedra, ele nos remeteria a um conjunto de significados latentes em seu interior. Um emblema condensa as diversas expressões sociais num traço material, tem a capacidade de resumir, na sua singularidade, a multiplicidade da vida em sociedade. Durkheim estava se referindo a um tipo de organização social, a tribo; o totem, enquanto emblema, poderia ser interpretado pelo sociólogo que decifraria os segredos sub-reptícios à sua manifestação icônica. A ideia de Ianni (que ele não desenvolve) é que o discurso sociológico opera por meio de um artifício taquigráfico. A taquigrafia é uma linguagem abreviada; da riqueza da língua ela retém apenas alguns traços; neste sentido, as notações taquigráficas encerram um grau de abstração que não coincide com a amplitude da realidade que representa. O emblema possui essa característica, reduz ao indício material uma realidade mais ampla. Quando afirmei que "as celebridades não constituíam ainda um emblema", queria dizer que havia um descompasso entre uma possível representação do real e sua manifestação social concreta. O hiato dizia respeito a essa defasagem.

Pode-se dizer que na esfera cultural, o século XX, em grande parte de sua extensão, privilegia outro emblema: a cultura de massa. Esse é o indício escolhido pelas ciências sociais para diagnosticar o "espírito da época". Quando Leo Lowenthal analisa o predomínio da biografia das pessoas do mundo do entretenimento em relação aos políticos, ele fala de "triunfo das massas", não das individualidades das pessoas biografadas. Porém, salta aos olhos que os termos do debate sobre a cultura de massa são quase homólogos (quase, eu digo) aos da discussão sobre as celebridades, ambos recobrem domínios afins. Partilham até a mesma virtude: ubiquidade. Lazarsfeld e Merton (I957) sublinham essa dimensão ao trabalhar a relação entre comunicação de massa e gosto popular. Por isso a televisão tornou-se o ícone de uma era; mais apropriada do que o cinema ou o rádio, na sua ubiquidade, ela representava uma "maneira de ser". A emergência da sociedade de massa encontra-se intimamente associada ao desenvolvimento do espaço público e à presença dos meios de comunicação. Lembro que esse é um tema caro à Escola de Chicago, nos Estados Unidos. Quando Cooley (I956) publica Social organization, em I902, 
apesar de os avanços técnicos, em termos de massa, serem ainda limitados, restringirem-se à imprensa, ele já nos fala de revolução comunicacional. Nos anos seguintes uma importante tradição sociológica sobre os meios de comunicação será desenvolvida (ver, entre outros, Lazarsfeld \& Staton, I942; Lerner \& Schramm, I967; Lasswell, I975). É sugestivo que tanto a problemática da cultura de massa quanto a das celebridades surjam primeiro nos Estados Unidos. Como se os passos da esfera cultural caminhassem em compasso com as mudanças do capitalismo moderno e contemporâneo. No que diz respeito à cultura de massa o contraste com a Europa Ocidental é interessante. Em meados do século XX o Velho Continente encontrava-se ainda mergulhado no caos do pós-guerra, tampouco conhecia um florescimento significativo da indústria do entretenimento: Hollywood, histórias em quadrinhos, publicidade etc. Por isso nos Estados Unidos percebe-se mais claramente como se estabelece uma nova configuração cultural: a presença de bens simbólicos capazes de penetrar o gosto das diferentes classes e camadas sociais. Cultura de massa nomeia essa dimensão do "homem médio" na qual a produção e a difusão cultural transformaram-se radicalmente. Ela é considerada de massa porque se insere num espaço partilhado "por todos", esse é o lugar público de sua circulação. O que só é possível graças à existência dos novos meios tecnológicos; toda a discussão da época fundamenta-se nesta premissa: para a circulação ampla dos bens culturais as transformações técnicas são imprescindíveis. Elas dão materialidade e funcionalidade ao sistema que se convencionou denominar "de massa". Um todo integrado no qual as partes encontravam-se interligadas por canais de comunicação. Não devemos nos esquecer de que essa sociedade é vista como algo inteiramente distinto das formações sociais anteriores; nesse sentido, ela não mais poderia ser considerada mera extensão da modernidade do século XIX.

Há ainda outros aspectos que aproximam a questão das celebridades à cultura de massa. O primeiro refere-se à noção de indivíduo. Grande parte da bibliografia recente ressalta esse ponto. Cito uma afirmação corrente nesses estudos:

Dois princípios básicos, que derivam das condições sociais e dos ideais da cultura americana, constituem a razão do surgimento das celebridades. Um é o individualismo o outro o igualitarismo. $O$ primeiro implica um sentido de direito, de mobilidade ilimitada das aspirações pessoais e uma expansiva concepção do Eu; o segundo ajuda a convencer as pessoas de que para se aceder ao status de celebridade não há necessidade de se possuir nenhum talento ou qualificação especial (Hollander, 2010: 390).

As celebridades são únicas, e sua relação com aqueles que as reconhecem é singular. Várias pesquisas empíricas, particularmente as vinculadas ao interacionismo simbólico, enfatizam essa dimensão (por exemplo, a relação com os fãs) (Ferris, 2004; 200I). Entretanto, esse é também um traço comum à problemática dos meios de comunicação. A noção de cultura de massa possui 
um antecessor ilustre: multidão. Esse era o termo empregado no século XIX para descrever o lado obscuro da sociedade industrial. Ou, como dizia Gustave Le Bon (1905), a psicologia das multidões consistia na negação do indivíduo; homogênea e amorfa, diluiria no seu interior o ser de cada um. O homem na multidão se comportaria como alguém possuído pelas forças incontroláveis de uma entidade coletiva. O Eu estaria submetido a uma "lei da unidade mental" que apagaria a idiossincrasia pessoal orientando os sentimentos e as ações num sentido alheio à sua consciência. Esse argumento prolonga-se no século $\mathrm{XX}$, e vários críticos da cultura de massa, à sua maneira, irão utilizá-lo; Adorno (I986b), por exemplo, insiste na ideia de pseudoindividualização. Temos às vezes tendência em perceber a discussão dessa época exclusivamente do ponto de vista crítico; esquece-se, porém, de que ele era minoritário, às vezes marginal, diante da hegemonia do pensamento liberal predominante na literatura sobre comunicação. Esse era o mainstream intelectual, principalmente nos Estados Unidos. Nesse caso, o termo massa, contrariamente à palavra multidão, adquire uma conotação positiva: é a expressão de uma individuação nunca antes conhecida. Edward Shils, por exemplo, dirá:

A sociedade de massa despertou e reforçou a individualidade. A individualidade caracteriza-se por uma abertura da experiência, o florescimento da sensação e da sensibilidade, sensibilidade em relação a outras mentes e personalidades... A sociedade de massa liberou as capacidades cognitivas, compreensivas e morais dos indivíduos. Um número maior de pessoas pode, conscientemente, aprender o valor do prazer dos olhos, ouvidos, gosto, tato, e convivibilidade. As pessoas fazem suas escolhas com maior liberdade em diversas esferas da vida, e essas escolhas não são necessariamente feitas por elas em nome da tradição, da autoridade ou da escassez (Shils, I964: 3).

Essa não é a visão de um único autor, pelo contrário, ela se torna um senso comum na literatura dedicada à modernização. Para nos darmos conta disso basta consultar um conhecido manual da época: Introductory Sociology (Cooley, Angell \& Lowell, I933). Há todo um capítulo sobre a personalidade no mundo moderno, e os meios de comunicação são descritos como poderosos instrumentos para "a abertura da mente humana". A ideia de que a sociedade de massa libera os indivíduos do constrangimento e pressão da tradição, da autoridade moral consagrada pelos costumes, é decisiva para os que veem a modernização como um progresso inelutável. Dentro dessa perspectiva os meios de comunicação têm um papel fundamental: jornal, rádio, televisão, filmes, teriam a virtude de oferecer aos indivíduos uma gama de oportunidades, retirando-os dos grilhões da tradição e integrando-os igualitariamente (essa era a ideologia) ao todo social. A oposição entre tradicional e moderno poderia, dessa forma, ser superada. Esse é o referencial teórico de vários estudos sobre América Latina, Oriente Médio e Ásia. A teoria da modernização queria compreender como esse processo, originário na Europa Ocidental, ten- 
do encontrado sua forma ideal nos Estados Unidos (uma visão americanocêntrica) estendia-se a outros países. Um exemplo sugestivo é o livro de Daniel Lerner (1958) sobre o Oriente Médio: The passing of tradition. Sua definição de personalidade móvel revela o quanto a noção de indivíduo, longe de se encontrar ausente da discussão sobre a sociedade de massa, na verdade, é um de seus pontos nevrálgicos:

A personalidade móvel pode ser descrita de maneira técnica e objetiva. A pessoa móvel distingue-se pela alta capacidade de identificação com o meio envolvente; ela está equipada com um conjunto de mecanismos necessários para incorporar as novas demandas que provêm de fora de sua experiência habitual. Essa é uma habilidade indispensável para as pessoas deixarem os seus territórios tradicionais (Lerner, 1958: 49-50).

No Oriente Médio, assim como na periferia do mundo, a modernização representaria a efetivação ideal do individualismo ocidental.

Outro aspecto que recobre o campo da cultura de massa e o das celebridades diz respeito à ideia de democratização. Esse é um traço amplamente explorado pela bibliografia especializada. Rojek (200I: I3) considera que a emergência das celebridades corresponde a uma série de transformações históricas: democratização da sociedade, declínio da religião organizada, mercantilização da vida cotidiana. David Marshall (I997: 7) é ainda mais preciso em sua avaliação: "Parece que o uso moderno do termo celebridade vincula-se à valorização da cultura popular e da cultura democrática. A celebridade materializa o empoderamento do povo que simbolicamente constitui a esfera pública". O raciocínio que sustenta esse tipo de argumentação repousa numa determinada concepção da história. Nas sociedades europeias do século XIX assiste-se ao fim dos privilégios de corte e da estratificação estamental do Antigo Regime. Essa ruptura favoreceria o surgimento de condições mais igualitárias. O advento do indivíduo moderno, na sua modalidade idiossincrática, coincidiria com a afirmação da democracia não tanto no nível político, como se entende habitualmente, mas no nível cultural e social. Leo Braudy (I986), um dos "clássicos" da área, termina seu livro The frenzy of renown com uma longa digressão sobre a democratização da fama nas sociedades contemporâneas; isso significaria o acesso ao sonho da aceitação social. Um exemplo bastante utilizado pelos autores, para se apreender a passagem da fase anterior, estamental e excludente, para uma ordem social mais aberta, diz respeito às publicações que classificam os indivíduos de renome. Esses catálogos de famosos cumprem uma função de distinção social; neles figuram os nomes das pessoas de notoriedade. Por exemplo, nos Estados Unidos, o International Celebrity Register, que utiliza como critério de classificação a visibilidade, aos poucos substitui o elitista Social Register, no qual a linhagem e a origem de classe eram os critérios de ordenamento das pessoas. Deixo de lado uma discussão mais substantiva da tese da democratização; em vários aspectos ela me pare- 
ce equívoca. Retomando o fio de meu raciocínio sublinho que o mesmo argumento perpassa a discussão sobre a cultura de massa. O surgimento de uma cultura popular produzida pelas indústrias culturais é um fato novo que desafia diretamente a cultura de elite. Diferentemente do século XIX, quando o popular associava-se à noção de folclore ou à cultura nacional, temos agora a produção e difusão de bens simbólicos em escala ampliada. Nos países "desenvolvidos" o popular associa-se às novas formas tecnológica - cinema, televisão, rádio, jornais -, deixando de representar a tradição contida nas festas populares, folguedos e brincadeiras. Por isso o embate e o debate sobre cultura popular e cultura de elite é acirrado. Contrariamente à ordem anterior, aristocrática ou burguesa, a sociedade de massa é percebida como promoção do espírito democrático, contraponto e negação do elitismo preexistente. É isso que Edward Shils (I964) quer dizer quando afirma que pela primeira vez na história dos homens o conjunto da população é incorporado ao centro da sociedade. Os que se encontravam à margem nas fases pré-modernas, os outsiders, estariam agora integrados ao todo que os excluía. Se a noção de cultura de elite fundamenta-se na ideia de separação - alguns dela fazem parte, outros não -, a de cultura de massa acentua a ideia de vínculo e integração. A tradição intelectual alemã cultivava a oposição entre kultur e civilização, com um claro predomínio da kultur sobre os valores materiais da indústria, do dinheiro e da técnica. O "Espírito", sempre com maiúscula, seria superior à matéria. No contexto da sociedade de massa há uma inversão dos valores, cultura de massa transforma-se em sinônimo de democracia. Esse é um ponto central da crítica de Adorno (I986a), o conceito de indústria cultural tem justamente a intenção de refutá-lo: ela seria uma integração deliberada (não espontânea e não democrática) a partir do alto.

\section{OS EMBLEMAS E A CORROSÃO DO TEMPO}

Se o emblema da cultura de massa foi convincente durante décadas, o que faz com que ele seja substituído por outro? Quais são as condições que impulsionam essa "mudança paradigmática"? O texto de Boorstin (I97I: 57) é seminal para entendermos esse processo. Primeiro, como observei, ele nomeia um objeto de maneira clara e explícita, estabelecendo parâmetros para a discussão posterior. Segundo - esse é o ponto que nos interessa -, sua definição do fenômeno: "a celebridade é uma pessoa conhecida pelo fato de ser bastante conhecida". A tautologia contida na frase é eloquente. Ela desloca nossas expectativas das qualidades intrínsecas à reputação de alguém para o sistema de construção do reconhecimento fundado na circulação de sua imagem. Esse é o traço essencial da celebridade, a circulação da imagem no espaço público. O jogo de contraste manifesto nesse enunciado pode ser apreendido através de outra formulação. James Monaco (I978: I4), crítico de arte que prematuramente escreve sobre as celebridades, coloca o problema da seguinte maneira: 
O primeiro teste da celebridade se passa quando existe um número significativo de pessoas que sabem o seu nome e reconhecem o seu rosto embora você não as conheça. Isso é protocelebridade. Um pouco de notoriedade numa profissão o levará a esse estágio. Porém, a verdadeira celebridade se confirma quando você realiza que existem outras imagens suas que nada têm a ver com o que você sabe sobre você mesmo. Ser citado na revista People é ser uma protocelebridade; ser incorretamente citado é ser uma verdadeira celebridade.

Dito de outra maneira, o status de celebridade só se confirma quando o conteúdo da pessoa torna-se secundário diante da sua representação pública. Vimos como Klapp considerava os personagens da cultura popular norte-americana parte de uma classificação que historicamente os antecedia, os antigos heróis. Entre eles e o passado não haveria um rompimento radical. Temos agora outro quadro de análise, estabelece-se uma ruptura entre a categoria de celebridade e a de herói, o que as diferencia é a ideia de achievement. Mesmo Braudy, cuja tese insiste sobre a continuidade da fama ao longo das sociedades humanas, passadas algumas décadas, é obrigado a reconhecer esse fato. Numa entrevista mais recente (Geddes, 2005a: 80), ele observa que "a fama, que antes vinculava-se à honra e era realçada pelas realizações, agora tornou-se tão separada desses atributos, que passa a existir como uma categoria própria, frequentemente desvalorizada e distante de algo que poderia parecer um resultado qualquer". O herói é um tipo social que realiza uma façanha extraordinária, destaca-se dos outros homens em função desse ato; seu valor, coragem ou força de caráter são os elementos que o impulsionam na direção da ação notável. Uma celebridade "nada faz" de excepcional, nada realiza, sua qualidade, dirá Boorstin, é a "ausência de qualidade". À solidez do herói substitui-se o efêmero de algo simplesmente conhecido e reconhecido. Esse é um traço recorrentemente realçado na bibliografia do tema. "Celebridade sugere efemeridade enquanto a fama ambiciona se estender à posteridade" (Epstein, 2005: 9). A fama repousa sobre fatos materiais incontestáveis, o efêmero é algo do presente, passageiro. Porém, a oposição herói versus celebridade não é uma mera diferenciação conceitual, ela demarca contextos históricos distintos. Houve um tempo dos heróis que cedeu lugar às celebridades.

A argumentação de Boorstin é sugestiva, embora não seja difícil vislumbrar suas debilidades. A tese central fundamenta-se numa perspectiva fortemente moralista, ele quer entender como o advento da imagem deprecia o alicerce espiritual da identidade norte-americana (o ensaio é um dos capítulos do livro The image: or what happened to the American dream). Seu ponto de partida é dúbio, pressupõe que a imagem distorça a realidade; nesse sentido, as celebridades seriam um "pseudoevento", algo que as afastaria de seu verdadeiro ser. Uma visão claramente ontológica do mundo na qual a inteireza das coisas se esvai quando elas são traduzidas imageticamente (qual seria a verdadeira natureza das coisas?). Boorstin (I97 I: 26) conclui seu texto da seguinte maneira: 


\begin{abstract}
Das irônicas frustrações de nossa época, nenhuma é mais irritante do que os nossos esforços artificiais para satisfazer as expectativas da grandeza humana. Em vão, e artificialmente, aumentamos a dimensão das celebridades, onde antes a natureza havia plantado a singeleza do herói. Logo que o herói começa a cantar ele se evapora na celebridade [...] Nessa vida de ilusão, ou semi-ilusão, a pessoa de virtudes sólidas, que pode ser admirada por algo mais substancial do que ser simplesmente conhecida, frequentemente transforma-se num herói calado [...] Seu anonimato a proteje do clarão efêmero da vida da celebridade.
\end{abstract}

Claramente o autor deplora o declínio de um certo Estados Unidos no qual os princípios éticos que o constituíam teriam fenecido. Entretanto, esse moralismo é expressivo, denota um conjunto de transformações subterrâneas à sociedade capitalista contemporânea. Nesse caso, não importam tanto os equívocos (eles existem), mas entender a que eles nos remetem. Dizer que a fama e a grandeza teriam cedido lugar ao renome fácil fabricado pelos meios de comunicação é fazer um diagnóstico dos novos tempos. Ora, a noção de achievement, característica do herói, compõe uma virtude essencial da ética capitalista tradicional. A distinção que Weber estabelece entre catolicismo e protestantismo é esclarecedora. Enquanto o catolicismo posterga a salvação pessoal para um mundo além dos homens, o protestantismo prega justamente o contrário, a salvação coincide com a realização das tarefas religiosas neste mundo. O sinal que permite reconhecê-la reside na constatação efetiva dos "feitos" (para falar como o herói) realizados na vida terrena. A ética protestante e a ética capitalista são homólogas porque fundamentam-se numa ação racional em direção a fins, a meta a ser alcançada deve ser tangível, o objetivo a ser conquistado. Achievement torna-se então uma virtude essencial do mundo capitalista. No fundo, o que Boorstin lamenta é a "corrosão do caráter" (utilizo como expressão o título do livro de Sennet, 200o) das pessoas; elas viveriam uma realidade na qual as disposições morais anteriores teriam sido revogadas. A valorização do efêmero sobrepõe-se assim à densidade de um capitalismo que se modifica, diz-se flexibiliza-se, desde as relações de trabalho até sua moral fundadora.

A questão do efêmero pode ser ainda mais bem desenvolvida. Retomo um debate esquecido que, pelo menos na França, no final do século XIX, mobilizou diversos intelectuais: a oposição entre luxo útil e luxo inútil (Ortiz, I99I). Os historiadores franceses costumam dividir o longo século XIX em dois momentos distintos. O primeiro refere-se à Revolução Industrial; ele se associa a um conjunto de inovações: estradas de ferro, iluminação a gás, telégrafo, fotografia. O segundo tem como substrato outro sistema técnico: automóvel, avião, eletricidade, cinema. Existe um ritmo diferenciado da modernidade, ela segue cadências distintas. Uma boa metáfora (Benjamin diria alegoria) para se apreender esse movimento é a passagem dos magasins de nouveautés para os grands magasins. Os magasins de nouveautés eram pequenas lojas de artigos diversos situadas geralmente nas passagens entre uma rua e outra; frequen- 
tados pela aristocracia em declínio e a burguesia ascendente, eles nos fazem esquecer que Paris, anterior à reforma do Barão Haussmann, encerrava uma dose considerável de tradição. As lojas de departamento, pelo contrário, são frutos da revolução da confecção que transforma radicalmente o panorama da produção e distribuição de vestimentas; são construções gigantescas, imponentes; Zola, em seu livro Le bonheur des dames, as denomina catedrais do consumo. A discussão a que me refiro situa-se no âmbito dessa "segunda modernidade". Quais são os termos do debate? Leroy-Beaulieu (I894: 87), crítico do luxo exagerado, dirá: "o luxo moderno, pelo menos aquele que não é depravado, consiste sobretudo em objetos duráveis, joias, mobílias, objetos de arte, coleções. É o que chamamos de capitais de fruição. Ele é bem superior ao luxo que se difunde nos objetos passageiros". Seus adversários pensam diferente: "Na simplicidade da vida, as necessidades seriam limitadas; mas numa sociedade estragada pela doçura da civilização, a paixão pelo supérfluo substituiu o sofrimento das privações individuais. O inútil tornou-se um elemento indispensável" (Saint-Germain, s/d: 6). Chamo a atenção para o fato de que o debate em curso distingue-se daqueles dos séculos anteriores, quando o luxo era aceito (argumentava-se que impulsionava a economia) ou simplesmente condenado (Rousseau o considerava uma degradação moral). Existem agora, dois tipos de luxo; eles se diferenciam em função da categoria utilidade. Uma polaridade de significados recobre a realidade social: durável/passageiro, neces sário/supérfluo, estável/instável, sendo que efêmero associa-se à inutilidade. Há uma clara correspondência entre o utilitarismo burguês e a valorização de luxo útil. O uso da riqueza dentro dos limites moralmente legítimos articula-se a uma ética do trabalho em consonância com o sistema produtivo. Surge então a pergunta: não haveria o risco de o luxo abusivo solapar a própria ética que lhe dá sustentação? (nos Estados Unidos, a ela Veblen [1899] procura responder em sua crítica ao consumo conspícuo). Não estou sugerindo a existência de uma sociedade de consumo no século XIX. Seria um contrassenso e um anacronismo de minha parte. A discussão sobre o luxo aponta apenas para algumas fissuras na ética capitalista prevalente. Por isso a metáfora da fábrica predomina sobre a moda (espaço por excelência do supérfluo); ela se ajusta melhor ao tempo da industrialização. O efêmero subjaz ao solo dessa modernidade industrial, ele é latente; é possível, aliás, localizar suas camadas geológicas, mas circunscreve-se a alguns aspectos da vida em sociedade. As transformações econômicas e sociais do final do século XX modificam o seu estatuto. Em seu livro La société de consommation Baudrillard (I970) mostra que o consumo não se esgota no ato de consumação de um determinado bem. O que se denomina sociedade de consumo reveste-se de uma especificidade: a utilidade dos objetos deixa de ser central para a sua realização. A dimensão funcional (um carro serve para dirigir; uma máquina de lavar roupas para lavar roupas) está enredada numa floresta de símbolos que vinculam o consumidor 
ao imaginário explorado pelas técnicas de publicidade e marketing. A escolha é parte de um universo que transcende a utilidade das coisas. Nesse contexto, o efêmero é redefinido, ele perde a conotação pejorativa que o envolvia, transformando-se em positividade inquestionável. As celebridades usufruem desse movimento de ressignificação, por fim adquirem o status de referente convincente, uma alegoria dos novos tempos.

A passagem de um emblema a outro implica a redefinição do passado. É preciso conceber e narrar os eventos anteriores de outra maneira. Nesse aspecto, creio que é possível aproximar a emergência da temática das celebridades a toda uma discussão feita nas ciências sociais a respeito das transformações do capitalismo contemporâneo. O prefixo "pós" exprime bem as mudanças em curso, ele distingue entre um antes e um depois (ver Ortiz, 2013). Em meados do século XX alguns sociólogos europeus e americanos já não mais se contentam em apreender a realidade que conhecem a partir da sociologia fundada no final do século XIX. As mudanças são substantivas e não se encaixam nos diagnósticos elaborados anteriormente. Por exemplo, Dahrendorf fala em sociedade "pós-capitalista" ao discutir como a propriedade dos meios de produção teria dado lugar a outras formas de autoridade, interesses e conflitos. Alain Touraine e Daniel Bell cunham o conceito de "sociedade pós-industrial" na qual as tecnologias têm um papel decisivo na organização social. Durante as décadas de I970 e I 980 surge uma série de metáforas que pretendem dar conta das transformações em curso: "sociedade da informação", "sociedade do conhecimento", "sociedade em rede" etc. A questão da pós-modernidade e da globalização deixa ainda mais claro o quadro de mudanças e, o que nos interessa, não se restringem à área econômica, atingem diretamente a esfera cultural. O emblema cultura de massa aos poucos começa a se desfazer, a realidade à qual se referia encontra-se em defasagem com a sua representação, e os significados que condensava cada vez mais tornam-se ininteligíveis. Consideremos o exemplo do best-seller de Alvin Tofler publicado em I980. Trata-se de um livro que pertence ao domínio do senso comum planetário; ele é sugestivo porque caracteriza a emergência de um novo tipo de intelectual que Lewis Coser (2006), de maneira arguta e irônica, denominou celebrity intelectual. O texto foi originalmente publicado em Dissent, na edição 20/I, em I973. Alguém que não se dirige aos seus pares no campo científico, mas, jogando com os conceitos e as expectativas do leitor, volta-se para o grande público. O texto revela alguns argumentos novos que se adaptam às mudanças em andamento. Diz Tofler (I980: I58): "[Na Segunda Onda, ou seja, a Revolução Industrial] a imagem produzida com centralismo, e injetada na mente pelos meios de massa, ajudou a produzir a padronização do comportamento ajustado ao sistema industrial de produção. Hoje, a Terceira Onda altera tudo isso. Os meios de massa, longe de expandir sua influência, subitamente se veem forçados a dividi-la. Em várias frentes, eles são batidos pelo que eu chamo de "mídia des- 
massificada". A sociedade de massa é dessa forma apreendida sob o signo da negatividade. Suas características seriam a centralização e a homogeneização, os indivíduos, longe de ser "livres", como se imaginava antes, apenas ajustariam seus comportamentos a um padrão estabelecido. Nesse sentido, ela tolheria o movimento e a individualidade das pessoas. Esse tipo de raciocínio é reforçado quando se consideram os próprios meios de comunicação: eles deixam de ser considerados "de massa". No meu esforço arqueológico de reconstrução dos argumentos, retomo um autor-chave da época, McLuhan (I964) (foi até protagonista de um filme de Woody Allen). Já em seu livro Undestanding media ele contrasta o padrão mecânico da sociedade industrial com o que denomina mundo elétrico. O primeiro seria centralizador, expandindo-se do centro para a margem; em contrapartida, a eletricidade descentraliza. Isso lhe permite afirmar: "A robótica é descentralizadora. Numa sociedade eletricamente configurada, todas as informações críticas, necessárias para a manufatura e a distribuição de carros a computadores, encontram-se, ao mesmo tempo, disponíveis para todos. A cultura se organiza assim como um circuito elétrico: cada ponto da rede é tão central como outro qualquer" (McLuhan \& Powers, I989: 92). O curioso na citação é a utilização da eletricidade como figura paradigmática. Soa um tanto desafinado para nossos ouvidos atuais, mas basta substituir o termo por eletrônico, digital, e a sensação de estranhamento desaparece. A eletricidade descrita contém as mesmas qualidades que atualmente atribuímos ao capitalismo flexível, à sociedade em rede. A cultura de massa, veiculada pelos meios de comunicação "antiquados", é então superada por uma configuração descentralizada, na qual os pontos da rede são autônomos e não estão "autoritariamente" articulados a um centro. O ícone televisão é rebaixado do Olimpo, sua hegemonia foi curta, sendo relegado a uma era fordista, rígida, anacrônica, retrato em sépia que nos faz admirar a flexibilidade célere (uma das etmologias da palavra celebridade) das ilusões atuais.

Recebido em 26/Io/20I5 | Aprovado em 25/oI/20I6 
690

Renato Ortiz é professor titular do Departamento de Sociologia da Unicamp e pesquisador I A do CNPq. Autor de diversos livros, entre eles, Cultura brasileira e identidade nacional (I985); A moderna tradição brasileira (I988); Mundialização e cultura (I994); O próximo e o distante: Japão e modernidade-mundo (2000); A diversidade dos sotaques: o inglês $e$ as ciências sociais (2008) e Universalismo e diversidade (20I5). 


\section{NOTAS}

I Os britânicos costumam adicionar a essa linhagem o livro de Richar Dyer (1979) Stars. Embora bem mais sistemático e desenvolvido do que os outros, o texto insere-se numa tradição anterior, o estudo do cinema, e não utiliza o conceito celebridade para analisar e descrever o mundo das "estrelas". Pode-se dizer o mesmo do artigo de Sherwin Rosen (I98I), "The economics of superstar".

2 Um exemplo é a colossal obra coordenada por Chris Rojek (20I0), editada em seis volumes, Celebrity: critical concepts on sociology.

3 Todas as citações foram traduzidas pelo autor [N.E.].

4 Ao que tudo indica modernité foi inventado por Baudelaire (I986). Sobre "civilização", consultar Starobinski (200I).

5 Consultar o belo livro de Nathalie Heinich (20I2), De la visibilité.

6 Entre os poucos autores que se recordam de citá-lo estão Alain Chenu \& Amy Jacobs (2010), "From path of glory to celebrity boulevard: sociology of Paris-Match covers, I945$2005 "$.

7 O livro de Barthes, Mythologies, é de I957; nele vamos encontrar um saboroso ensaio, bastante citado na bibliografia das celebridades: "Le visage de Garbo".

8 Na bibliografia norte-americana Charles Lindbergh é uma espécie de modelo exemplar de celebridade. Sua figura é recorrentemente analisada e comentada por inúmeros autores.

\section{REFERÊNCIAS BIBLIOGRÁFICAS}

Adorno, Theodor. (I986a). A indústria cultural. In: Cohn, Gabriel (org.). Theodor Adorno: Sociologia. (Col. Grandes Cientistas Sociais). São Paulo: Ática.

Adorno, Theodor. (1986b). Sobre Música Popular. In: Cohn, Gabriel (org.). Theodor Adorno: Sociologia. (Col. Grandes Cientistas Sociais). São Paulo: Ática.

Alberone, Francesco. (I963). L'elite senza potere. Milão: Vita e Pensiero. 
Barry, Elizabeth (2008). Celebrity, cultural production and public life. International Journal of Cultural Studies, I I/3, p. 25 I-258.

Barthes, Roland. (1957). Mythologies. Paris: Seuil. Baudelaire, Charles. (1986). Le peintre de la vie moderne. In: Écrits esthétiques. Paris: Union Générale d'Éditions.

Baudrillard, Jean. (I970). La société de consommation. Paris: Denoel.

Boorstin, Daniel. (I97I). The image: or what happened to the American dream. Nova York: Atheneum.

Braudy, Leo. (1986). The frenzy of renown: fame and its history. Nova York: Vintage Books.

Carrol, John. (20I0). The tragicomedy of celebrity. Society, 47. Cashmore, Ernest. (2006). Celebrity culture. Londres: Routledge.

Chenu, Alain \& Jacobs, Amy. (2010). From path of glory to celebrity of boulevard: sociology of Paris-Match covers, 1945-2005. Revue Française de Sociologie, 5I, suppl. (Annual English Selection), p. 69- I 6.

Cooley, Charles H. (I956) [I902]. Social organization. Glencoe: The Free Press.

Cooley, Charles H.; Angell, Robert C. \& Carr, Lowell J. (1933). Introductory Sociology. Nova York: Charles Scriber's Son.

Coser, Lewis. (2006). The intellectuals as celebrity. In: Etizioni, Amitai \& Bowditch, Alyssa (orgs.). Public intellectuals: an endangered species?. Maryland: Rowman \& Littlefield.

Drake, Philip \& Miah, Andy. (2010). The cultural politics of celebrity. Cultural Politics, 6/I, p. 49-64.

Dyer, Richard. (1979). Stars. Londres: British Film Institute Publishing.

Epstein, Joseph. (2005). Celebrity culture. The Hedgehog Review, 7/I, p. 7-20.

Ferris, Kerry O. (2007). The sociology of celebrity. Sociology Compass, I/I, p. 37 I-384.

Ferris, Kerry O. (2004). Seeing and beeing seen: the moral order of celebrity sightings. Journal of Contemporary Ethnography, 33/3, p. 236-264. 
Ferris, Kerry O. (200I). Through a glass, darkly: the dynamics of fan-celebrity encounters. Simbolic Interaction, 24/I, p. 25-47.

Friedman, Hershey \& Friedman, Linda. (I979). Endorser effectiveness by product type. Journal of Advertising Research, I9/5, p. 63-7I.

Friedman, Hershey et al. (1978). Correlation of trutsworthiness for celebrities. Academy of Marketing Science, 6/4, p. 29I-299.

Furedi, Frank. (2010). Celebrity culture. Society, 47/6, p. 493497.

Gamson, Joshua. (I 994). Claims to fame: celebrity in contemporary America. Berkeley: University of California Press.

Gamson, Joshua. (I992). The assembly line of greatness: celebrity in $20^{\text {th }}$ century America. Critical Studies in Mass Communication, 9/I, p. I-24.

Garland, Robert. (2010). Celebrity ancient and modern. Sociology, 47/6, p. 484-488.

Geddes, Jennifer L. (2005a). An interview with Leo Braudy. The Hedgehog Review, 7/I, p. 78-8I.

Geddes, Jennifer L. (2005b). An interview with Richard Schickel. The Hedgehog Review, 7/I, p. 82-87.

Harmon, Kristine. (2005). Celebrity culture: bibliography review. The Hedgehog Review, 7/I, p. 98-106.

Heinichi, Nathalie. (2012). De la visibilité: excellence et singularité en régime médiatique. Paris: Gallimard.

Heinich, Nathalie. (20I Ia). La consommation de la célébrité. L’Année Sociologique, 6r/s, p. I03-I 23.

Heinich, Nathalie. (20I Ib). La culture de la célébrité en France et dans les pays anglophones. Revue Française de Sociologie, 52/2, p. 353-372.

Hobsbawm, Eric. (2009). As revoluções burguesas. Rio de Janeiro: Paz e Terra (vol. I).

Hollander, Paul. (2010). Why the celebrity cult? Sociology, 47/5, p. 388-39I.

Howell, Brian. (2007). Fame us: celebrity impersonators and the cult(ure) of the fame. Vancouver: Arsenal Pulp Press. 
Ianni, Octavio. (I 994). Globalização: novo paradigma das ciências sociais. Estudos Avançados, 8/2I, p. I47-I63.

Inglis, Fred. (2010). A short history of celebrity. Princeton: Princeton University Press.

Jeffrey, Alexander C. (2010). The celebrity-icon. Cultural Sociology, 4/3, p. 323-336.

Klapp, Orrin E. (1949). Hero worship in America. American Sociological Review, I4/I, p. 53-62.

Kurzman, Charlie et al. (2007). Celebrity status. Sociological Theory, 25/4, p. 347-367.

Langbauer, Laurie. (I993). The celebrity economy of cultural studies. Victorian Studies, 36/4, p. 466-472.

Lasswell, Harold. (I975). A estrutura e a função da comunicação na sociedade. In: Cohn, Gabriel (org.). Comunicação e indústria cultural. São Paulo: Cia. Editora Nacional.

Lazarsfeld, Paul \& Merton, Robert (I957). Mass communication, popular taste and organized social action. In: Rosenberg, Bernard \& White, David (orgs.). Mass culture: the popular arts in America. Nova York: The Free Press.

Lazarsfeld, Paul \& Staton, Frank (orgs.). (I942). Radio research. Nova York: Duell Sloan and Pearce.

Le Bon, Gustave. (I905) [1895]. Psychologie des foules. Paris: Félix Alcan.

Lerner, Daniel. (I958). The passing of tradition. Nova York: Free Press.

Lerner, Daniel \& Schramm, Wilbur (orgs.). (I967). Communication and change in developing countries. Honolulu: EastWest Center Press.

Leroy-Beaulieu, Paul. (I894). Le luxe: la fonction de la richesse. Revue des Deux Mondes, I26, I ${ }^{\mathrm{er}}$ novembre, p. 72-100. Leslie, Larry Z. (20II). Celebrity in the $2 \mathrm{I}^{\text {st }}$ Century. Santa Barbara: Contemporary Issues.

Lilti, Antoine. (2014). Figures publiques: l'invention de la célébrité. Paris: Fayard.

Lowenthal, Leo. (I984) [1944]. The triumph of mass idols. In: Literature and mass culture. New Brunswick/Londres: Transaction Books. 
Marshall, David. P. (20I0). The specular economy. Society, 47/6, p. 498-502.

Marshall, David P. (org.). (2006). The celebrity culture reader. Londres: Routledge.

Marshall, David P. (I997). Celebrity and power: fame in contemporary culture. Minneapolis: University of Minnesota Press.

Mauss, Marcel. (1968). Une catégorie de l'esprit humain: la notion de personne, celle de moi. In: Sociologie et anthropologie. Paris: PUF.

McLuhan, Marshall. (1964). Understanding media. Nova York: McGraw Hill Book Co.

McLuhan, Marshall \& Powers, Bruce R. (I989). The global village. Oxford: Oxford University Press.

McKernan, Brian. (200I). Politics and celebrity: a sociological understanding. Sociological Compass, 5/3, p. 190-202.

Milner Jr., Murray. (2010). Is celebrity a new kind of status system?. Society, 47/5, p. 379-387.

Monaco, James. (1978). Celebration. In: Monaco, James (org.). Celebrity. Nova York: Delta.

Morin, Edgar. (I972) [I957]. Les stars. Paris: Seuil.

Morin, Edgar. (1962). L'esprit du temps. Paris: Grasset.

Ortiz, Renato (2013). Ruptura e continuidade: dilemas da contemporaneidade. In: Gadea, Carlos \& Barros, Eduardo P. (orgs.). A questão do pós nas ciências sociais. Curitiba: Appris. Ortiz, Renato. (2009). Globalização: notas sobre um debate. Sociedade e Estado, 24/I, p. 23I-254.

Ortiz, Renato. (I99I). Cultura e modernidade: a França no século XIX. São Paulo: Brasiliense.

Payne, Tom. (2009). Fame: what the classics tell us about our cult of celebrity. Nova York: Picador.

Ponce de Leon, Charles L. (2002). Self-exposure human-interest journalism and the emergence of celebrity in America I890I 940. Chapel Hill: University of North Carolina Press.

Powdermaker H. (I950). Hollywood: the dream factory. An anthropologist looks at the movie-makers. Boston: Little-Brown. Redmond, Sean \& Holmes, Su (orgs.). (2006). Framing celebrity. Nova York: Routledge. 
Rein, Irving J. et al. (1987). High visibility. Nova York: Dodd Mead.

Rojek, Chris (org.). (2010). Celebrity: critical concepts on sociology. Nova York: Routledge (6 vols.).

Rojek, Chris. (200I). Celebrity. Londres: Reaktion Books.

Rosen, Sherwin. (I98I). The economics of superstars. The American Economic Review, 7I/5, p. 845-858.

Ruebsaat, Norbert. (2007). Seen by many: the celebrity image. In: Howell, Brian (org.). Fame us: celebrity impersonator and the culture of fame. Vancouver: Arsenal Pulp Press.

Saint-Germain, J. T. (s/d). Éloge du luxe effrené des femmes. Paris: Jules Tardieu Ed.

Schickel, Richard. (2010). Blog therefore I am. Society, 47/6, p. 52 I-524.

Schikel, Richard. (1985). Intimate strangers: the cult of celebrity. Nova York: Doubleday.

Schneider, Joseph. (1936). Fame and social origin. Social Forces, I4/3, p. 354-36I.

Sennett, Richard. (2000). A corrosão do caráter: consequências pessoais do trabalho no novo capitalismo. Rio de Janeiro: Record.

Shils, Edward. (1964). Mass society and its culture. In: Jacobs, Norman (org.). Culture for millions? Boston: Beacon Press.

Starobinski, Jean. (200I). A palavra civilização. In: As máscaras da civilização. São Paulo: Companhia das Letras.

Tarde, Gabriel. (1902). Psychologie économique. Paris: Félix Alcan.

Tillyard, Stella. (2005). Celebrity in the $18^{\text {th }}$ century London. History Today, 55/6, p. 20-27.

Tofler, Alvin. (1980). The third wave. Nova York: Bantam Books.

Turner, Graeme. (2004). Understanding celebrity. Londres: Sage.

West, Darrel M. (2005). American politics in the age of celebrity. The Hedgehog Review, 7/I, p. 59-65. 
Palavras-chave

Sociologia da cultura;

Teoria sociológica; Mundo contemporâneo;

Celebridades;

Cultura de massa.

\section{Keywords}

Cultural sociology;

Sociological theory; Contemporary world;

Celebrities; Mass culture.

\section{AS CELEBRIDADES COMO EMBLEMA SOCIOLÓGICO}

\section{Resumo}

O debate sobre as celebridades é recente nas ciências sociais. Os primeiros ensaios sobre a questão datam de I970I 980 . O texto pergunta o motivo disso. A resposta dada pelo autor é que as celebridades não constituíam ainda um emblema sociológico capaz de nele condensar um conjunto de sentidos que "falassem" do mundo contemporâneo. O texto procura mostrar como na esfera cultural o emblema da "cultura de massa" dominou os estudos sociológicos até o momento em que a noção de massa cede lugar à de "diferença”, "flexibilização", na qual o sujeito se impõe sobre a homogeneidade postulada anteriormente.

\section{CELEBRITIES AS A SOCIOLOGICAL EMBLEM}

\section{Abstract}

The debate on celebrities in the social sciences is recent. The first essays on the topic date from the I970s and 80s. The author argues that celebrities did not yet constitute what he terms a sociological emblem. The text shows how the emblem of 'mass culture' predominated in the cultural sphere until the notion of mass became surpassed by the ideas of 'difference' and 'flexibility,' a new context in which the individual imposes on the homogeneity postulated previously. 